\title{
Anal Fissure: A Frequent Reason of Anal Pain
}

\author{
Dr. Bhavin Kothari \\ Associate Professor, Department of Surgery, Gujarat Adani Institute of Medical Sciences, Bhuj, Gujarat, India
}

\begin{abstract}
Benign anorectal disorders are common and increasing in incidence. The decreasing intake in dietary fiber over the 20th century and into the 21st has contributed to a steady rise in preventable anorectal disorders. Anal fissure is a linear ulcer in the squamous epithelium of the anal canal located just distal to the dentate line. It is usually located in the posterior midline but occurs anteriorly in a fifth or more or patients. It typically causes pain during defaecation which may last for 1-2 h afterwards. is one of the most common anal diseases. It is characterized by anal pain on or after defecation and often by bright blood on the toilet paper. The pathogenesis of chronic anal fissure is not completely understood. Anal fissures presents mostly in children aged 6-24 months. The overall incidence in children is not well described. Most fissures heal spontaneously, but conservative management with ointment and fiber supplementation will relieve the pain and promote healing of those that do not. However, for a subgroup of patients with fissures refractory to medical therapy who are at risk of incontinence or are reluctant to undergo the gold standard surgical treatment of lateral internal sphincterotomy.
\end{abstract}

Keywords: Anal fissure, ointment, sphincterotomy, ulcer

\section{Introduction}

Benign anorectal disorders are common and increasing in incidence. The decreasing intake in dietary fiber over the 20 th century and into the 21 st has contributed to a steady rise in preventable anorectal disorders. Anal fissure is a linear ulcer in the squamous epithelium of the anal canal located just distal to the dentate line. It is usually located in the posterior midline but occurs anteriorly in a fifth or more or patients. It typically causes pain during defaecation which may last for $1-2 \mathrm{~h}$ afterwards ${ }^{1}$. The most consistent finding on physical examination is spasm of the anal canal due to hypertonia of the internal anal sphincter. It has been postulated that this may either be due to or be the result of ischaemia ${ }^{2}$. Delayed diagnosis and treatment can lead to a disturbing cycle of constipation; repeat rectal bleeding, and crying, due to increasing pain during and after defecation. In spite of its high frequency, the problem remains underrated by most clinicians, with only a paucity of data on the management of anal fissures in children being found in the literature. For many years it was thought that passage of a hard large stool during a period of constipation tore the anoderm causing a fissure. Autopsy studies have found that the blood supply to the anoderm at the posterior midline is significantly lower than the other sides of the anal canal ${ }^{3}$.

\section{Aetiology}

The aetiology of the typical fissure is not clear. Trauma from passing a large or hard stool is a common initiator ${ }^{4}$, but many traumatic fissures heal and others do not. Resting anal pressure is higher in patients with an anal fissure 5 . Ambulatory manometry has shown persisting high anal resting tone interpreted as due to hypertonia of the internal anal sphincter with poor spontaneous relaxation in patients with a chronic fissure ${ }^{6}$. The aetiology of fissure formation in females who have had a vaginal delivery whether complicated or assisted or in patients with a rectocele may be different. Scar formation may be associated with ischaemia and poor healing, but in addition resting sphincter pressure is low ${ }^{7}$. If the fissure is not situated in the midline or if it is multiple or painless, the association with other pathologies should be considered. These include Crohn's disease, ulcerative colitis, HIV and associated secondary infections, tuberculosis, syphilis, and neoplasia including leukaemia or carcinoma.

\section{Incidence and Etiology}

Anal fissures presents mostly in children aged 6-24 months. The overall incidence in children is not well described. Anal fissures are located in the posterior midline in $90 \%$ of the cases, although $10-20 \%$ in women and $1-10 \%$ in men are located in the anterior midline ${ }^{8}$. The posterior commissure of the anoderm is less well perfused than other anodermal regions. Pressure over the branches of the inferior rectal artery causes relative ischemia.

\section{Clinical Picture}

The clinical picture involves a history of constipation in $20 \%$ of the cases, intense crying with bowel movements, streaks of bright red blood on the surface of hard stool, on the diaper, or on the toilet paper, following bowel movements, discharge and pruritus. The clinical hallmark of anal fissure is pain during, and especially some time after defecation. Inspection of the anal region reveals a posterior midline laceration, a sentinel skin tag, and signs of inflammation.

\section{Treatment Options}

\section{Medical Treatment}

More than $90 \%$ of fissures heal spontaneously. Symptomatic fissures warrant treatment. Conservative management is the first line of therapy. Increasing dietary fiber and water intake should be coupled with fiber supplementation. In addition to increasing dietary fiber, patients should begin fiber supplementation once a day, and if that is tolerated, their dosage should be increased to twice a day within a week. Patients should drink at least two glasses of water or fluids each time they take a fiber supplement dose. A laxative, such as two tablespoons milk of magnesia once or twice a day, is added for patients with persistent constipation despite increased fiber intake. Stool softeners such as docusate can

\section{Volume 4 Issue 11, November 2015}




\section{International Journal of Science and Research (IJSR) \\ ISSN (Online): 2319-7064}

Index Copernicus Value (2013): 6.14 | Impact Factor (2014): 5.611

also be added to the fiber regimen. A sitz bath in warm water once or twice a day for ten minutes may offer some relief. Lidocaine $2 \%$ jelly is prescribed to reduce pain as needed before and after bowel movements. Lidocaine $2 \%$ jelly is prescribed to reduce pain as needed before and after bowel movements. Steroid-based creams and hemorrhoidal ointments are usually not effective. Ointments such as nitroglycerin $0.2 \%$ to $0.3 \%$, diltiazem $2 \%$, and nifedipine $0.03 \%$ can heal symptomatic fissures; their reported success rate is between $30 \%$ and $70 \% .2-4,7-11$ Diltiazem $2 \%$, applied three times daily and five minutes prior to a bowel movement, is our ointment of choice and has a higher rate of fissure healing than nitroglycerin does and can heal fissures that have been unsuccessfully treated with nitroglycerin. ${ }^{9}$ The relaxation of sphincter tone induced by diltiazem, nitroglycerin, and nifedipine can relieve the pain within a few days, but complete healing may take up to two months. Patients should be reassessed at one month; if there is persistent fissure but decreased symptoms, the ointment should be continued for another month.

\section{Surgical Treatment}

Patients in whom medical therapy fails may be candidates for surgical intervention. The timing of intervention depends on the initial response to conservative therapy and on symptom severity. Patients with severe anal pain can be offered surgical intervention if no improvement is seen within a week. Injection of botulinum toxin type A into the internal sphincter can lead to symptomatic relief and healing of some fissures. However, in many patients the relief is temporary and long-term fissure recurrence is common, often making additional injections necessary. ${ }^{10}$

\section{Anal Dilatation}

First described in 1829 by Recamier and popularized by Lord in the treatment of hemorrhoids, anal stretching has been used in the past based on the concept of loosening the sphincter muscle and increasing the blood flow to the anoderm. Anal dilatations was reintroduced for anal fissure therapy in 1964 , with success rates of $87 \%$ to $100 \%$, but are not recommended in children because of the very high rate of recurrence, risk of sphincter damage and incontinence after excessive stretching.

\section{Fissurectomy}

Fissurectomy as a treatment for anal fissures in children was found successful only when combined with postoperative laxative therapy ${ }^{11}$. An important part of their technique was the use of stay sutures to avoid the need for an anal retractor, thereby preventing stretching of the internal anal sphincter. A triangular part of the anoderm is excised along with the fissure itself. A good and reliable operation, but leaves behind a large and uncomfortable external wound, which takes a long time to heal. Application of a split thickness graft to the wound has been advocated, in order to improve healing.

\section{Anal Advancement Flap}

An anal advancement flap is effective in healing an anal fissure and is followed by minor complications only. It should be recommended in patients with a low resting anal pressure. Various flaps have been described but a rotational or V-Y flap may reduce complications. An island flap in which a circumcised area of perianal skin is advanced proximally to cover the fissure has been shown to be effective in healing with no incidence of incontinence ${ }^{12,13}$. An alternative to this is a $\mathrm{V}-\mathrm{Y}$ advancement flap or a rotational flap, which are both associated with lower rates of donor site wound complications, reported to be as high as $60 \%{ }^{14}$.

\section{Lateral Internal Sphincterotomy}

However, for a subgroup of patients with fissures refractory to medical therapy who are at risk of incontinence or are reluctant to undergo the gold standard surgical treatment of lateral internal sphincterotomy. we have combined injection of botulinum with fissurectomy. Debridement of the fibrotic edges of a chronic fissure can stimulate healing when combined with fissurectomy. ${ }^{15}$ typically we inject 60 to 80 units of botulinum toxin type A into the internal sphincter muscle; we have seen complete fissure resolution in many patients. The most effective surgical treatment of chronic anal fissure is LIS. LIS can heal more than $90 \%$ of fissures refractory to medical therapy within eight weeks and is associated with a very low recurrence rate of less than $10 \%$. LIS involves cutting a small portion of the distal aspect of the internal sphincter muscle. The internal sphincter muscle contributes to baseline and resting continence. Spasm of this muscle results in severe anal pain and constricts blood flow to the fissure area. Releasing a portion of the muscle yields rapid symptomatic relief and heals the fissure. Overall, the procedure is safe and can be done under local anesthesia with intravenous sedation in most patients. The complication rate is low. A subgroup of patients may experience transient and temporary gas incontinence.

\section{Conclusion}

Anal fissure is the most common cause of severe anal pain and bleeding seen in the primary care setting, in urgent care and surgical clinics, and in Emergency Departments. Most fissures heal spontaneously, but conservative management with ointment and fiber supplementation will relieve the pain and promote healing of those that do not. Surgical intervention is reserved for patients in whom conservative treatment fails.

\section{References}

[1] Edwards FC, Truelove SC. The course and prognosis of ulcerative colitis. Gut 1963; 4: 299-315.

[2] Hawthorne AB, Travis SPL, the BSG IBD Clinical Trials Network. Outcome of inpatient management of severe ulcerative colitis: a BSG IBD Clinical Trials Network Survey. Gut 2002; 50: A16.

[3] Klosterhalfen B.,Vogel P., Rixen H.,Mittermayer C. Topography of the inferior rectal artery : a possible 


\section{International Journal of Science and Research (IJSR) \\ ISSN (Online): 2319-7064}

Index Copernicus Value (2013): 6.14 | Impact Factor (2014): 5.611

cause of chronic, primary anal fissure. Dis Colon Rectum, 1989, 32 : 43-52.

[4] Don BA, Goldacre MJ. Absence of seasonality in emergency hospital admissions for inflammatory bowel disease. Lancet 1984; 2: 1156-7.

[5] Hardy TL, Bulmer E. Ulcerative colitis: survey of 95 cases. Br Med J 1933; ii: 812-5.

[6] Miller CG, Gardner CMcG, Ripstein CB. Primary resection of the colon in ulcerative colitis. Can Med Assoc J 1949; 60: 584.

[7] Travis SPL, Farrant JM, Ricketts C et al. Predicting outcome in severe ulcerative colitis. Gut 1996; 38: 90510.

[8] Notaras, M.J.). Anal fissure and stenosis. The Surgical Clinics of North America 198868 ; (6) 1427-1440.

[9] Jonas M, Speake W, Scholefield JH. Diltiazem heals glyceryl trinitrate-resistant chronic anal fissures: a prospective study. Dis Colon Rectum 2002; 45(8):1091-5.

[10] De Nardi PD, Ortolano E, Radaelli G, Staudacher C. Comparison of glycerine trinitrate and botulinum toxinA for the treatment of chronic anal fissure: long-term results. Dis Colon Rectum 2006; 49(4):427-32.

[11] Lambe, G.F., Driver, C.P., Morton, S., \& Turnock, R.R. Fissurectomy as a treatment for anal fissures in children. Annals of the Royal College of Surgeons of England 2000 82; (4): 254-257.

[12] Philpotts LE, Heiken JP, Westcott MA, Gore RM. Colitis: use of CT findings in differential diagnosis. Radiology 1994; 190: 445-9.

[13]Fishman EK, Kavuru M, Jones $B$ et al. Pseudomembranous colitis: CT evaluation of 26 cases. Radiology 1991; 180: 57-60.

[14] Ramachandran I, Sinha R, Rodgers PM. Pseudomembranous colitis revisited: spectrum of imaging findings. Clin Radiol 2006; 61: 535-44.

[15] Eccles M, Mason J. How to develop cost-conscious guidelines. Health Technol Assess 2001; 5: 1-69. 